\title{
Marginalisation of Roma: Root Causes and Possible Policy Actions
}

\author{
PAVEL CIAIAN and D’ARTIS KANCS \\ Directorate-General Joint Research Centre, European Commission, Via Enrico \\ Fermi 2749, I-21027 Ispra (VA), Italy. Email: pavel.ciaian@ec.europa.eu
}

\begin{abstract}
The existing policy and academic debate on the social mobility of Roma have been focused almost entirely on entry barriers (the cost of entry into the mainstream society), whereas exit barriers (the cost of exit from the traditional Roma lifestyle) have been acknowledged and studied to a much lesser extent. In this study we advocate that from a policy perspective it is important to understand differences between the two types of social mobility barriers, as they have different causes and hence have to be addressed by different policy instruments. However, it is important that both types of social mobility barriers are addressed simultaneously, as they interact and reinforce each other mutually. Further, addressing social mobility barriers of Roma requires a change of both formal and informal institutions. Therefore, policy measures have to be implemented and sustained over a long period of time in order to have a sustainable impact on the social and economic integration of Roma.
\end{abstract}

\section{Introduction}

The current paper attempts to understand causes of the social and economic marginalisation of Roma in Europe, in particular, the role of social mobility barriers. Ciaian and $\mathrm{Kancs}^{1}$ have identified two types of social mobility barriers for Roma: (i) self-isolation and the cost of exit from the Roma community; and (ii) discrimination and the cost of entry into the mainstream socio-economic system. The self-isolation and the cost of exit define to what extent informal Roma institutions support or inhibit their members leaving their community and accepting interactions with the mainstream socio-economic system. The cost of entry determines to what extent the mainstream population is willing to accept Roma within their socio-economic structures and share the common infrastructure with Roma. The acceptance of Roma is a particularly important precondition, given that the mainstream population controls all major socio-economic infrastructures as well as it defines gains that Roma can realise outside their own community. 
Most of the existing policy and academic debate on the social and economic marginalisation of Roma has been focused almost entirely on entry barriers. However, in order to design effective policy responses, it is important to understand both types of social mobility barriers for Roma. Further, from a policy perspective, it is important to acknowledge and understand that the two types of social mobility barriers - the cost of exit from the traditional Roma community and the cost of entry into the mainstream society - have different causes and hence have to be addressed by different policy instruments. It is equally important that both types of social mobility barriers are addressed simultaneously, as they interact and reinforce each other mutually. However, any policy action targeted to address the two social mobility barriers needs to take into account local conditions, as their relative importance varies strongly among communities, regions and countries. As regards the policy measures' effectiveness in addressing the two types of social mobility barriers, they need to be implemented and maintained over a long period of time to generate strong enough signals necessary to induce institutional changes in the attitudes and expectations of both Roma and non-Roma. Any short-term policy attempts without addressing the underlying institutional framework will fail to change the current status quo of the social and economic marginalisation of Roma.

\section{Self-isolation and the Cost of Exit}

As detailed in Ciaian and Kancs, ${ }^{1}$ Roma are governed by informal institutions, which substitute formal state institutions to sustain a specific social order. The informal institutions of Roma include a set of rules (or law), called Romaniya, which govern the conduct of members of the Roma community. Romaniya contains a complex system of rules based on a superstitious belief system, it is selfsustaining, it contains own-enforcement mechanism, and prescribes a system of societal organisation..$^{2-4}$

Beliefs enshrined within Romaniya imply a whole series of boundaries to the outside environment and have direct and indirect implications for the social and economic behaviour of Roma. As explained in Ciaian and Kancs, ${ }^{1}$ an important source of impurity and pollution are non-Roma, their places and objects, because they do not obey Romaniya rules. Most importantly, the belief system based on marimé, that non-Roma are inherently polluted, plays a key role in ensuring its self-enforcement and makes exit from Roma society or interaction with non-Roma costly.

Roma use the term gaje to refer to all non-Roma. Originally, it translates as peasants or uncivilised or uneducated persons, but it also has connotation equivalent to 'barbarians' in English. ${ }^{4}$

The Gypsies generally view the gaje as having no sense of justice or decency. ... Furthermore, not only do the Gypsies consider non-Gypsies polluted, they also believe that Gypsy names and rituals lose their magical effectiveness if uttered to gaje. Consequently, the Gypsies believe they should approach and respond to the gaje with caution, especially if the gaje profess good intentions. (Ref. 4, p. 25) 
This perception of gaje is motivated by the fact that they do not conform to rules of 'clean' behaviour, as established by Romaniya. As noted by Sutherland, ${ }^{5}$

[b]ecause they [non-Roma] do not observe body separation, non-Gypsies are a source of impurity and disease. Public places where non-Gypsies predominate such as public toilets, hospitals buses, schools, offices, jails, and non-Gypsy homes are also potential sources of disease. All these places are less 'clean' than the home of a Gypsy or open outdoor spaces such as parks and woods. When they must be in non-Gypsy places, Gypsies generally avoid touching as many impure surfaces as possible, but, of course, prolonged occupation of a non-Gypsy place such as a hospital means certain impurity. In this case the person tries to lessen the pollution risk by using disposable paper cups, plates, and towels - that is, things not used by non-Gypsies. (Ref. 5, p. 1)

Generally, Roma perceive non-Roma as having no sense of righteousness and good conduct. Even the behaviour of non-Roma that is in line with their own norms and formal rules is considered as immoral and unjust by Roma, if it does not conform with Romaniya. ${ }^{4}$

A strict enforcement of Romaniya implies wide-reaching restrictions for Roma in all aspects of the social and economic life. According to Romaniya, Roma need to abstain from any socio-economic interactions with the mainstream society, except for those vital for the survival of Roma. Given that any unnecessary contact with nonRoma needs to be avoided, it implies a self-isolation of Roma from mainstream society. Hence, the informal institutions of Roma create certain 'boundaries', which separate external and internal environments and require behaviour that maintains distance from mainstream society. Informal Roma rules inflict self-isolation from the surrounding society and economy, leading to a failure to realise potential benefits (e.g. from the gains of specialisation and trade) that would arise in the absence of selfisolation. This element of Romaniya plays a central and reinforcing role in the selfisolation and contributes to its sustainability, as it implies low payoffs for outside options. The threat of pollution from interactions with non-Roma increases the cost of exit although, economically, it would be beneficial to collaborate with mainstream society.

Due to exit barriers, in traditional Roma communities socio-economic interactions between Roma and non-Roma are minimal and usually they do not go beyond the minimum necessary interactions. As Gropper ${ }^{6}$ states

the economic sphere of life is the only link between [Roma] and gaje among whom they live. (Ref. 6, p. 30)

As regards social interactions, because of Romaniya, many Roma do not allow nonRoma to enter the private living spaces of their homes, although, in special cases, they may permit them to enter certain areas (e.g. front rooms) after taking a number of precautions. For example, by providing a special seat reserved for non-Roma or by using special cups, dishes and utensils - to avoid contamination if food or drink is offered to non-Roma. ${ }^{3}$ Analogously, food prepared by non-Roma is considered as polluted and thus needs to be avoided. ${ }^{7}$ To avoid marimé, Roma would reject food prepared outside the Roma community (e.g. in restaurants, hospitals, prisons), which 
may inhibit contact with non-Roma. A strategy often used to reduce the pollution risks when eating away-from-home food is to use disposable dishes and cutlery, ${ }^{8}$ to eat pre-packed food and to drink from cartons or bottles. ${ }^{3,4}$ For example, to avoid pollution, Roma patients may refuse food prepared by non-Roma in the hospital cafeteria, and prefer consuming homemade food instead. ${ }^{9}$

In situations where it is not possible to completely avoid interactions with nonRoma, precautions must be undertaken to avoid contamination. Usually, however, complete isolation from non-Roma is impossible. For survival reasons, Roma need to enter into economic transactions with non-Roma, because non-Roma control the major part of the economy. In order to minimise contacts with non-Roma while ensuring economic survival, a typical Roma strategy is to engage in autonomous-type occupations and to take certain precautionary measures. For example, in their fortune-telling businesses, Roma cover seats with a protective slip to prevent nonRoma polluting them. ${ }^{3}$ Generally, many Roma rely on trade and service activities, which do not depend on non-Roma or require entering into conventional wagelabour relations. Economic activities based on self-employment (as opposed to wagelabour) allow Roma to adopt a flexible and detached lifestyle from non-Roma. In addition, this permits Roma to be independent from and unconstrained by a particular economic structure and skill requirements (to particular forms of production). It allows Roma to be operationally flexible and able to easily exploit new market opportunities and economic circumstances. ${ }^{10,11}$ Ultimately, these fundamental structures of Roma economic institutions importantly contribute to sustaining their social and economic autonomy from non-Roma.

All this provides the Roma with a notion of greater freedom and hence superiority over the [Gaje]. (Ref. 10, p. 6).

Based on the fieldwork about Roma musicians (lăutari) in Romania, Beissinger ${ }^{13}$ finds that their integration with non-Roma is limited solely to economic interactions, although, lăutari perceive themselves as a superior cultural group within the Roma community, which has strong common links with the mainstream population:

Lautari fundamentally socialize only with other lautari, creating and perpetuating close, in-group relations based on occupation and ethnicity... in the many times that I have been in their home, other lăutari have dropped by to talk, drink, and play music on a regular basis, but other non-lăutar Romani visitors have been very rare. Not once in my stays with them, however, has a Romanian ever paid a social visit; Romanians stop by only to discuss performance arrangements (dates, payments, and so on). (Ref. 12, p. 39-40).

Another area, where the self-imposed boundaries imply isolation of Roma from mainstream society, is children's education. Traditionally, Roma educate their children within families and the Roma community. Roma parents tend to avoid sending their children to non-Roma schools, as this poses a threat of contamination and alienation. A critical period is during the puberty of children when they become subject to marimé, implying that certain activities need to be avoided (e.g. threats of pollution, joint sexual education of boys and girls) and thus it is a common reason for 
parents to withdraw their children from school. ${ }^{10}$ Alongside professional education, an important part of the Roma self-education process is children's acquaintance with and learning of community rules and values. ${ }^{10,11}$ This behaviour contributes to the sustainability of the Roma specific social order, as it facilitates the inter-generational transfer of knowledge related to survival strategies (self-employment skills), community beliefs and rules.

The Casa-Nova's ${ }^{13}$ study of the Roma community in northern Portugal shows that children's close contact with family and community members is fundamental in transferring the occupational knowledge and intra-community societal values to them. Roma children learn community rules and occupation through daily contact and observation (and imitation) of their parents or other adults in the community. Parents usually take their children to fairs from a young age, so that they can learn skills and gradually become able to conduct various tasks required by this profession.

\section{Discrimination and the Cost of Entry}

The anti-Roma discrimination by mainstream society plays an important role in preserving (reinforcing) the separation between Roma and non-Roma in two segregated society groups. The willingness to accept Roma by the mainstream population is rather limited due to the pervasiveness of anti-Roma discrimination. As discussed by Ciaian and Kancs, ${ }^{1}$ anti-Roma discrimination has become historically rooted over centuries of repressive policies and discriminatory attitudes from the mainstream population.

Schooling is a particularly good example of the segregation and marginalisation of Roma children. Many Roma parents are reluctant to send their children to mainstream schools because of the hostile attitudes toward Roma children of non-Roma children and parents (also often of teachers), attitudes that are widely observed in schools in Europe. ${ }^{14}$ This hostile behaviour increases the social costs of Roma children acquiring a formal education, as they may face emotional and/or physical abuse when attending a mainstream school. Such a hostile environment reinforces the demarcation between Roma and non-Roma (i.e. it increases the entry costs), thus reducing the chances of a successfully completing school and so lowering the probability of finding employment. ${ }^{10}$

Another example, where anti-Roma discrimination increases the cost of entry, is the mainstream labour market. Anti-Roma discrimination restricts the access of Roma to employment, which reduces job opportunities for Roma on the mainstream labour market. First, due to the anti-Roma discrimination, Roma face a lower level of the labour force participation and a higher level of unemployment compared with non-Roma who share similar characteristics, location and social infrastructure. ${ }^{15,16}$ Second, as discussed in Ciaian and Kancs, ${ }^{1}$ even if employed, Roma receive a lower wage for an equivalent job, compared with non-Roma. ${ }^{17,18}$ Third, anti-Roma discrimination crowds-out Roma to low-skill jobs. Kahanec ${ }^{19}$ argues that, because Roma face high entry barriers into the mainstream labour market, it is likely that those Roma that succeed in overcoming the barriers possess superior skills compared 
with their non-Roma counterparts, as they are not exposed to a comparable discrimination.

\section{Discrimination, Self-isolation and Interaction}

From a policy perspective, key questions are to what extent the social and economic marginalisation of the Roma population is induced by the self-isolation enshrined by Romaniya rules, and to what extent is anti-Roma discrimination exercised by mainstream society? In order to identify, design and implement efficient policy measures, one needs to understand these two phenomena and isolate their impact on the social and economic marginalisation of Roma.

Findings from Sections 2 and 3 suggest that both the self-imposed isolation of Roma and the anti-Roma discrimination by mainstream society may mutually reinforce each other and thus may be responsible for the segregation of Roma and non-Roma into two parallel societies. On the one hand, anti-Roma discrimination contributes to a negative perception of Roma by non-Roma. On the other hand, the negative discriminatory experience of Roma tends to strengthen the Roma's negative perception of non-Roma, and it reinforces acceptance of the correctness of the Romaniya belief system, that gaje are inherently impure. Further, Romaniya's internal rules that require avoiding any interactions with non-Roma, and tolerate an adverse behaviour towards non-Roma, generate distrust towards Roma from mainstream society and fuel further discriminatory behaviour. The behaviour of both Roma and non-Roma is guided by a mutual belief that the other group is dishonest and employs unfair practices, and this justifies a negative attitude towards the other group. While anti-Roma discrimination reinforces the negative attitude of Roma towards non-Roma, the induced response in the Roma behaviour contributes to creating negative stereotypes about Roma and a negative perception by mainstream society, strengthening the discrimination of Roma. Hence, it is a vicious circle, where mutual attitudes and the behaviour of Roma and non-Roma are self-reinforcing.

One central reason for the social and economic marginalisation of Roma is centuries of anti-Roma discrimination, which has affected the behaviour of Roma. To cope with discriminatory attitudes and policies imposed on them (slavery, expulsion, genocide, forced assimilation), particularly prior to the middle of the twentieth century, Roma had to adapt and invent various survival strategies. Sway ${ }^{11}$ identifies several strategies that allowed Roma to survive in the hostile environment imposed by mainstream society, strategies that enabled them to exploit various niche and marginal markets that were unattractive to the mainstream population.

In response to the labour market discrimination, Roma have adopted several alternative occupation-related strategies: (i) nomadism; (ii) exploiting available resources viewed as worthless by the mainstream population; (iii) avoiding a genderbiased division of labour; (iv) avoiding age barriers in the labour supply; (v) becoming multi-occupational; and (vi) entering into semi legal or illegal activities to bypass the discriminatory regulations of economic activities imposed on them. Nomadism allows Roma to flexibly exploit market opportunities dispersed across different 
locations, according to local needs, by moving to locations where gaps in the labour supply and demand arise in the host society. ${ }^{20}$ Nomadism also enables Roma to address the seasonality issue of many low-skill occupations (e.g. between the winter and summer periods) by moving to locations where economic opportunities are available (e.g. a typical summer occupation is fortune telling, entertainment and casual agricultural works, while in winter Roma tend to move to more densely populated areas dealing, for example, with used cars, collection of scrap metals). ${ }^{11}$ Roma usually do not face a moral barrier in exploiting available resources that are viewed as worthless or even humiliating by the mainstream population. Such activities are perceived as acceptable or honourable and allow Roma to exploit market segments disregarded by the mainstream population (e.g. collecting of scrap metal, brick manufacturing, rag collection, manufacture of wooden objects, etc.). ${ }^{11}$ Roma tend to avoid gender bias at work, as they have no cultural predisposition to enforce a specific division of labour between men and women. They allocate tasks within the family to maximise family (community) benefits. For example, if the fortune-telling business of women is successful, all family members adapt their activities to support the women, without causing an embarrassment for men (e.g. men may assume responsibility for advertising, obtaining consumers, child care). ${ }^{11}$ Similarly, Roma tend to avoid age barriers when allocating work responsibilities within families or communities. All members of the family or community are expected to contribute to earning a living, a contribution that usually reflects the comparative advantage of a particular age group. For example, children may contribute with auxiliary labour in the family business, or perform certain activities where they have a better predisposition than adults (e.g. begging). Elder adults may contribute to the income of the Roma family or community by qualifying for welfare benefits. ${ }^{11}$ Further, Roma tend to diversify occupations by being active in multiple economic activities, which provide a certain 'security of income' and enable them to flexibly adapt when some occupations cease to be profitable or become forbidden by the mainstream population. ${ }^{11}$ As discussed in previous sections, yet another survival strategy is to enter into semi-legal or illegal activities to bypass the discriminatory regulations of economic activities imposed on them (e.g. procuring false documents, involvement in petty crimes such as stealing to cope with occupational restrictions). ${ }^{2}$

In response to the social discrimination, Roma have also adjusted their lifestyle by: (vii) locating in less accessible territories or regions to be out of the reach of public authorities; and (viii) concentrating in large groups to facilitate self-protection and safety-net provision. One common strategy applied to cope with anti-Roma discrimination and the repressive policies of mainstream society in Europe, particularly prior to the Second World War, was to locate themselves in remote regions (e.g. inaccessible wastelands or forests) or border regions, where the access of public authorities is limited. In addition, nowadays Roma often settle in segregated communities, either in rural areas or in city suburbs. ${ }^{21,22}$ Lawless et al. ${ }^{21}$ argues regarding the idea of autonomy that Roma 
have often sought peripheral locations on the edge of cities because in such locations they may be able to minimise the interference of social control agencies and to maintain their cultural separation from the defining gaje. (Ref. 21, p. 120)

Hence, one can argue that the spatial self-isolation of Roma is an outcome of the combined effect of anti-Roma discrimination and the self-imposed isolation of Roma. ${ }^{23}$ In addition, there is widespread a resistance to the registration of births and marriages among Roma. ${ }^{24}$ The preference of Roma for self-education and a reluctance towards formal schooling is reinforced by the hostile attitudes of non-Roma children and parents (also often of teachers) towards Roma children, which is widely observed in schools in several European countries. Such a hostile environment is conducive to strengthening the belief and perception among Roma children about the inherently polluted non-Roma value system. ${ }^{10,14}$ Further, as a response to the social and physical discrimination by mainstream society, Roma often tend to concentrate in large communities to facilitate self-protection. This allows Roma to protect themselves against state authorities with an anti-Roma bias or from physical discrimination by the mainstream population. Further, the concentration of Roma in monolithic communities allows them to sustain the social fabric of their institutions and the social order, and it creates an environment that can provide a safety net for their lifestyle against an adverse external environment (discrimination).

Most of these Roma survival strategies, adopted over centuries, are considered to be outside of the social norms of mainstream society, which further fuels anti-Roma discrimination. Hence, discrimination triggers an adoptive behaviour that may be beyond the social norms of mainstream society, which in turn causes further discrimination.

Besides the anti-Roma discrimination, the informal Romaniya rules also contribute to the social and economic marginalisation of Roma. Some elements of the Roma-specific behaviour described in Section 2 reinforce the resentment of the mainstream population, ultimately being reflected in an even stronger discriminatory behaviour.

As regards the self-isolation on the labour market, Roma usually try to avoid occupations (e.g. wage-labour relations) that imply working under gaje. ${ }^{1}$ The selfimposed isolation of Roma, embodied within informal Roma institutions, leads to adverse networking effects reflected in the reduced availability of opportunities linked to labour markets or other economic activities. This inward-looking nature of Roma's social relationships magnifies the economic exclusion and reduces the availability of economic opportunities through networking. ${ }^{25}$ For example, as argued in Ciaian and Kancs, ${ }^{1}$ social networking is found to be an important determinant in accessing labour market opportunities in the presence of asymmetric information and search costs. ${ }^{26-28}$ This is reinforced by discriminatory attitudes against Roma and thus further exacerbates the social networking effect. Discriminatory attitudes reflect the resentment of Roma by the mainstream population and imply the exclusion of Roma from mainstream social networks. If, instead, the social interaction were not hampered by discrimination and self-imposed isolation, this could facilitate a better 
understanding and inter-group exchange of information about the actual abilities and skills of Roma and thus could improve their prospects in the labour market.

As regards the educational self-isolation, Roma children are traditionally educated at home within families by involving them in family activities (professions). Children observe, participate, and gradually take over responsibilities of the family business. As discussed in Ciaian and Kancs, ${ }^{1}$ Roma perceive schools as a gaje world, which represents a particular threat to their children's educational development. It conflicts with the Roma value system, as it is in breach of the traditional Roma educational habits and it carries the danger of alienating Roma children from their own traditions and beliefs. ${ }^{10,13}$ Moreover, the traditional Roma educational requirements are, in general, incompatible with the mainstream schooling system, which relies on a specialised external (away from family) form of education. This generates frictions with the mainstream schooling system, often resulting in the low educational attainment rates of Roma pupils. Additionally, a family-based education limits Roma children's acquisition of skills other than those available and/or necessary within the own community.

An important implication of this behaviour is that Roma children may fail to obtain formal school degrees, resulting in discrimination on the labour market. Because of a lack of formal school diplomas and certified job experience, the selfimposed isolation in education and the labour market, the access of Roma to the formal and legal job market is limited.

\section{Policies for Reducing Social Mobility Barriers}

As discussed above, the self-isolation (exit barriers) and the anti-Roma discrimination (entry barriers) are interrelated social phenomena of the Roma and non-Roma coexistence and they need to be considered jointly for understanding the social (im) mobility of Roma. As discussed in Section 2, the self-isolation and exit costs are sustained by a Roma-specific belief system and are reinforced by anti-Roma discrimination, while Roma beliefs about the inherent impurity of non-Roma and the associated behaviour strengthen the anti-Roma discrimination prevalent in mainstream society. Any societal changes (including policies) affecting either the nonRoma or Roma population might impact both the anti-Roma discrimination and the Roma belief system. If Roma informal institutions are altered through a policy or any other change in the external environment, it might impact directly on the selfisolation and the exit cost of Roma and indirectly on the anti-Roma discrimination by shifting the non-Roma's perception about Roma. Instead, if the anti-Roma discrimination is altered by a policy or an external change, it might have a direct effect on the entry cost of Roma into mainstream society and an indirect feedback effect on Roma beliefs about non-Roma.

It must be recognised that a reduction or elimination of social mobility barriers for Roma is a long-term process that may take several generations to be fully realised. Changing anti-Roma discrimination requires changes in the perceptions and beliefs of mainstream society about Roma. Given that the anti-Roma discriminatory 
attitudes by mainstream society have been in place over many centuries, their replacement requires changes in the functioning of public institutions as well as changes in the behaviour of society. Further, as discussed in Section 4, anti-Roma discrimination reinforces the Roma's belief system and their informal institutions, which are strengthened by attitudes and pressures coming from mainstream society over a long period and represent a protection or safety environment against external adverse behaviour (discrimination). To alter this equilibrium in the behaviour of Roma and non-Roma requires changing beliefs and perceptions of both Roma and non-Roma. Following the theory of endogenous institutional change, an institutional change is an evolutionary process, where beliefs and perceptions that guide a society's behaviour adjust gradually to policy or changes in the external environment. The underlying change needs to be persistent and consistent to induce institutional adjustments. Further, this theory argues that there is a strong path dependency of formal and informal institutions, where past institutional patterns tend to persist over long periods of time due to various factors, such as asymmetric information, sunk costs of coordination, free-rider problems and uncertainties, and thus any policy change may not induce an institutional change if it is not sufficiently strong and sustained over a sufficiently long time period. ${ }^{29-33}$

A key driver of institutional change is change in the belief system. ${ }^{29-32,34}$ According to Greif ${ }^{30}$ and Greif and Laitin, ${ }^{31}$ changes in informal institutions can occur due to endogenous processes, exogenous shocks, e.g. policy interventions, or a combination of both, resulting in changes in beliefs and the associated behaviour of its members.

An institutional change is a change in beliefs, and it occurs when the associated behaviour is no longer self-enforcing, leading individuals to act in a manner that does not reproduce the associated beliefs. (Ref. 31, p. 639)

In order to be sustainable, a change in Roma behaviour (e.g. mistrust towards nonRoma) must be associated with changes in beliefs or expectations about the other community's behaviour. A source of such a change could be policies targeting Roma beliefs about non-Roma. Examples of specific policies could include various social integration policies promoting inter-cultural exchanges, promotion of public awareness or provision of social support or assistance to Roma communities without changing their underlying lifestyle. Such polices would target the exit cost side of social mobility barriers faced by Roma and thus would improve their acceptance of the socio-economic cooperation and interaction with non-Roma. In turn, a policyinduced higher acceptance of non-Roma by Roma may increase the inter-societal trust and reduce the self-isolating behaviour of Roma, which could have a positive feedback on reducing discriminatory attitudes by the mainstream population.

A critical element to enhance the social mobility of Roma is the issue of the entry costs into mainstream society associated with anti-Roma discrimination. In the presence of anti-Roma discrimination, Roma cannot realise the gains form socioeconomic interactions with non-Roma even if the self-isolation and the exit cost were absent. In contrast, in the absence of anti-Roma discrimination, the socio-economic 
opportunities available within mainstream society could be fully exploited and thus increase the opportunity costs of the self-isolation, which would subsequently improve the social mobility of Roma. Reducing anti-Roma discrimination could also have a significant feedback repercussion for the Roma belief system. It may foster Roma communities breaking away from the existing belief system and moving towards new beliefs that accommodate interactions and cooperation with non-Roma (though not necessarily changing the whole underlying belief system and the lifestyle). Without a significant reduction of the anti-Roma discrimination by mainstream society, the transition away from self-isolation towards integration with the mainstream would be severely hindered. Instead, the negative attitudes of Roma towards non-Roma may remain in place in the Roma belief system, and thus contribute to the self-isolation.

Fundamental for facilitating the adjustment of the Roma belief system and hence reducing their social mobility barriers is recognising the fact that the Roma's belief system (and thus self-isolation), and the anti-Roma discrimination by mainstream society are interlinked. The self-exclusion of Roma and the associated beliefs could be altered if the negative attitudes of non-Roma were to decrease, which could be attained by a sustained non-discriminatory policy in all spheres of socio-economic life. Note that such a policy needs to be maintained over a long period of time, because changes in Roma behaviour (e.g. mistrust towards non-Roma) require changes in their belief system and in the expectations of the whole community, requiring several generations. Beliefs need to readjust to incorporate outcomes and expectation that Roma can obtain through interactions with mainstream society. ${ }^{29-33}$ Any ad hoc and/or short-term policy intervention applied to the discrimination issue of Roma may fall short of representing a credible structural change in mainstream society's attitude towards Roma and thus may fail to change the Roma belief system about their outside opportunities.

An important policy that could alleviate the entry barriers of Roma by improving their outside opportunities, represents positive discrimination, through giving preferential treatment, especially in children's education and in the labour market. Another important area of policy action could include targeting the negative perceptions and prejudices about Roma through media and various public awareness programmes. The negative stereotyping of Roma is often supported by the mass media, which helps to maintain negative anti-Roma attitudes among the mainstream population. Articles published about Roma in the mass media are often presented without an accurate and thorough analysis of the context behind the reported story and tend to reproduce racist stereotypes and prejudices prevalent within the mainstream population. ${ }^{35-38}$

Policies addressing the entry barriers of the Roma social mobility are similarly expected to have a positive multiplier feedback on anti-Roma discrimination. The improved attitudes towards Roma (e.g. if anti-Roma discrimination is eliminated) may unlock the negative Roma belief about non-Roma, which may lead to reduced dishonest Roma behaviour towards non-Roma and ultimately may increase the mutual trust and further reduce the discriminatory attitudes of mainstream society. 
In summary, a crucial element of any policy action is that any policy initiative addressing social mobility barriers for Roma needs to be implemented and sustained over a long period of time in order to be credible and to have a sustainable impact on reducing the social and economic marginalisation of Roma. Policies need to provide persistent signals to Roma of their equal (or favourable) opportunities outside their community, which will guide individual behaviour and provide stimulus for an endogenous institutional change within the Roma community as well as change perceptions of non-Roma about Roma. Second, both exit and entry barriers need to be addressed simultaneously, as they are interlinked.

\section{Conclusions and Policy Implications}

The current paper studies the causes of the social and economic marginalisation of Roma; in particular, the role of social mobility barriers. We have identified two types of social mobility barriers for Roma: the cost of exit from the traditional Roma community and the cost of entry into mainstream society. Entry barriers determine to what extent mainstream society is willing to accept Roma within its socio-economic structures which, as shown in this paper, are often discriminatory. Since their arrival in Europe in the fifteenth century, Roma have faced direct discriminatory attitudes from mainstream society and institutionalised discrimination - as reflected in antiRoma policies ranging from expulsion measures and forced assimilation up to enslavement - which has been imposed by state authorities across Europe, and which has lasted for over six centuries. Only after the Second World War did attitudes towards Roma start to change, when integration became one of the main European policy paradigms to address the problems associated with the social and economic marginalisation of minorities. However, even in the presence of the improved policy framework, anti-Roma discrimination has largely remained in place, up to the present day, in most social and economic spheres.

The anti-Roma discrimination poses a major problem for the social mobility of Roma, as it constrains their integration into and interactions with mainstream society. More precisely, anti-Roma discrimination reduces Roma benefits from the socio-economic opportunities outside their community, such as education and the labour market. Overall, anti-Roma discrimination plays an important role in preserving the segregation between Roma and non-Roma in two parallel social groups.

In this article, we argue that another important factor that restricts the social mobility of Roma is the Roma-specific informal institution called Romaniya. Romaniya contains a complex system of rules based on a superstitious belief system. It incentivises its members to sustain a socio-economic order separate from mainstream society, and it relies on a ritual belief system whose core concept is distinguishing between behaviour that is polluted (marimé) and pure (vujo). Marimé has important implications for Roma, as it determines actions and behaviour that are accepted and are in line with the Romaniya social order. Given that non-Roma are considered as inherently polluted. A strict enforcement of Romaniya implies widereaching restrictions for Roma in all aspects of social and economic life. According to 
Romaniya, Roma need to abstain from any interactions with the Roma society, except for those interactions vital for the survival of Roma. The belief enshrined within the Romaniya that non-Roma are inherently polluted plays an important role in ensuring Romaniya's self-enforcement and makes an exit from the Roma society or interactions with non-Roma costly. More precisely, the outside opportunities available within mainstream society (such as education and employment) are perceived as undesirable, and are sanctioned within Romaniya. Through the selfimposed isolation, Romaniya contributes to the social and economic marginalisation of Roma.

Further, the findings of our article suggest that both exit barriers (self-isolation and exit costs) and entry barriers (anti-Roma discrimination) reinforce each other and are responsible for the segregation of Roma and non-Roma in two parallel societies. On the one hand, the anti-Roma discrimination contributes to preserving the negative perceptions of Roma about non-Roma, and harmful discriminatory experiences of Roma tend to strengthen their negative perception about non-Roma while reinforcing views about the correctness of the Romaniya belief system that non-Roma are inherently impure (dishonest). On the other hand, Romaniya's internal rules require avoiding any interactions with non-Roma, and tolerate a detrimental behaviour towards non-Roma. The isolated traditional lifestyle generates distrust towards Roma in mainstream society and triggers further discriminatory behaviour. Hence, it is a vicious circle, where mutually adverse attitudes and behaviour between Roma and non-Roma are self-reinforcing.

The findings of this article suggest that, from a policy perspective, it is important to acknowledge and understand that the two types of social mobility barriers - the cost of exit from traditional Roma society and the cost of entry into mainstream society have different causes and hence have to be addressed by different policy instruments. It is also important that both types of social mobility barriers are addressed simultaneously when designing policies, as they interact and reinforce each other mutually.

Policies targeting the exit barriers to social mobility could include the promotion and introductions of various social integration policies promoting inter-cultural exchanges, public awareness or social assistance. These type of polices target the exit costs of social mobility barriers faced by Roma and thus may improve their acceptance of socio-economic cooperation and interaction with non-Roma. Policies targeting the entry barriers to social mobility could include measures that promote a positive discrimination of Roma in various socio-economic areas (e.g. education and employment) and that target the negative perceptions of non-Roma about Roma in media and various public awareness programmes. It is important that any policy measure needs to be implemented and sustained over a long period of time to have a sustainable impact on reducing the social and economic marginalisation of Roma. It needs to provide a persistent signal to Roma of their equal (or favourable) opportunities outside their community.

Although differentiated policies should be designed to address the exit and entry barriers of the Roma's social mobility, it needs to be recognised that their effectiveness will be limited if they are not undertaken simultaneously. As argued in this 
article, the exit barrier is sustained by the Roma specific belief system and is reinforced by anti-Roma discrimination, whereas the Roma beliefs about the inherent impurity of non-Roma are strengthened by anti-Roma discrimination prevalent in mainstream society. Further, a critical element to enhance the social mobility of Roma is the issue of entry barriers into mainstream society because, due to antiRoma discrimination, Roma cannot realise gains from socio-economic interactions with non-Roma even if the exit barriers were absent.

The findings of this article have to be considered, however, with some caution and need to account for the underlying assumptions implicitly imposed in the above analysis. In the current study we have investigated a number of stylised facts, such as the adherence of Roma to Romaniya. However, in reality the application of Romaniya varies from community to community. A number of studies have shown that the adherence of Roma to Romaniya's traditional value system has reduced to some extent in some European Roma communities over the last decades. ${ }^{39-41}$ Thus, when analysing social mobility barriers for Roma (i.e. entry and exit barriers) or designing policy responses, one has to understand the local conditions and the relative importance of the two types of social mobility barriers in the particular place in order to be able to propose effective and efficient policy solutions.

\section{Acknowledgements}

The authors acknowledge helpful comments and valuable contributions from Enrica Chiozza, Marta Garcia Fidalgo and Julda Kielyte. This paper is developed following the methodologic framework of Ciaian and Kancs. ${ }^{1}$ The authors are solely responsible for the content of the article. The views expressed are purely those of the authors and may not be regarded as stating an official position of the European Commission.

\section{References and Notes}

1. P. Ciaian and D. Kancs (2016) Causes of the social and economic marginalisation: The role of social mobility barriers for Roma. JRC Technical Report No. 27794 (Luxembourg: Publications Office of the European Union).

2. A. Fraser (1995) The Gypsies (Oxford: Wiley-Blackwell).

3. P.T. Leeson (2013) Gypsy law. Public Choice, 155, pp. 273-292.

4. W.O. Weyrauch (Ed.) (2001) Gypsy Law: Romani Legal Traditions and Culture (Berkeley: University of California Press).

5. A. Sutherland (2015) Cross-cultural medicine: A decade later. Patrin < http:// www.oocities.org/ patrin/healthus.htm >

6. R.C. Gropper (1975) Gypsies in the City: Culture Patterns and Survival (Princeton, NJ: Darwin Press).

7. The exceptions are children; they may eat food prepared by non-Roma given that they are less subject to the marimé rule.

8. Roma may simply eat with their hands rather than use cutlery that may not have been properly washed.

9. D. Honer and P. Hoppie (2004) The enigma of the Gypsy patient. $R N, 6$ 7(8), pp. 33-36. 
10. Y. Matras (2015) Roma culture: An introduction. Roma Culture, Project Education of Roma Children in Europe Project, Council of Europe.

11. M. Sway (1984) Economic adaptability the case study of the Gypsies. Urban Life, 13(1), pp. 83-98.

12. M.H. Beissinger (2001) Occupation and ethnicity: Constructing identity among professional Romani (Gypsy) musicians in Romania. Slavic Review, 60(1), pp. 2449.

13. M.J. Casa-Nova (2007) Gypsies, ethnicity and the labour market: An introduction. Romani Studies, 17(1), pp. 103-123.

14. G. Kertesi and G. Kézdi (2013) Ethnic segregation between Hungarian schools: Long-run trends and geographic distribution. Hungarian Statistical Review, 16, pp. 18-45.

15. UNDP (2005) Faces of Poverty, Faces of Hope (United Nations Development Programme).

16. European Commission (2012) The situation of Roma in 11 EU Member States: Survey results at a glance. Results of the UNDP/World Bank/European Commission regional Roma 2011 survey. Report prepared by FRA and UNDP (Luxembourg: Publications Office of the European Union).

17. G. Kertesi and G. Kezdi (2011) Roma employment in Hungary after the postcommunist transition. Economics of Transition, 19(3), pp. 563-610.

18. N. Drydakis (2012) Roma women in Athenian firms: Do they face wage bias? Ethnic and Racial Studies, 35(12), pp. 2054-2074.

19. P. Ciaian and D. Kancs (2018) Social mobility barriers for Roma: Discrimination and informal institutions. European Review, 26(4), pp. 670-685. doi: 10.1017/S1062798718000352.

20. Note that nowadays not all Roma communities are nomads. Many of them have adopted a sedentary lifestyle.

21. P. Lawless, R. Martin and S. Hardy (1997) Unemployment and Social Exclusion: Landscapes of Labour Marginality (London: Jessica Kingsley).

22. D. Sibley (1998) The problematic nature of exclusion. Geoforum, 29, pp. 119-121.

23. Two other reasons for the spatial self-isolation could be the outcome of economic deprivation and missing employment opportunities, and the self-exclusion embodied in Romaniya.

24. R. Creţan and D. Turnock (2009) The Gypsy minority in Romania: A study in marginality. Romanian. Journal of Geography, 53(1), pp. 33-56.

25. D. Smith and M. Greenfields (2012) Housed Gypsies and travellers in the UK: Work, exclusion and adaptation. Race Class, 53(3), pp. 48-64.

26. K.J. Arrow (1998) What has economics to say about racial discrimination? Journal of Economic Perspectives, 12(2), pp. 91-100.

27. J.D. Montgomery (1991) Social networks and labour-market outcomes: Toward an economic analysis. American Economic Review, 81, pp. 1408-1418.

28. D. Kancs and J. Kielyte (2010) Education in the East, emigrating to the West? European Review, 18(2), pp. 133-154.

29. M. Aoki (2007) Endogenising institutions and institutional changes. Journal of Institutional Economics, 3(1), pp. 1-31.

30. P. Ciaian, A. Ivanov and D. Kancs (2018) Long-run economic, budgetary and fiscal effects of Roma integration policies. JRC Technical Report (Luxembourg: Publications Office of the European Union).

31. A. Greif and D.D. Laitin (2004) A theory of endogenous institutional change. American Political Science Review, 98(4), pp. 633-652. 
32. R. Myerson (2004) Justice, institutions, and multiple equilibria. Chicago Journal of International Law, 5, pp. 91-107.

33. C. Kingston and G. Caballero (2009) Comparing theories of institutional change. Journal of Institutional Economics, 5(2), pp. 151-180.

34. P. Ciaian, J. Pokrivčák and D. Kancs (2012) The rise and fall of enforcement institutions: An example of religion and secularism. European Review, 20(2), pp. 233-251.

35. E. Di Giovanni (2014) Contemporary anti-Gypsyism in European mass media. International Journal of Social, Management, Economics and Business Engineering, 8(12), pp. 3491-3494.

36. R. Morris (2000) Gypsies, travellers and the media: Press regulation and racism in the UK. Communications Law, 5(6), pp. 213-219.

37. M. Stewart (2012) The Gypsy Menace: Populism and the New Anti-Gypsy Politics (London: Hurst).

38. V. Vidra and J. Fox (2014) Mainstreaming of racist anti-Roma discourses in the media in Hungary. Journal of Immigrant and Refugee Studies, 12(4), pp. 437-455.

39. A. Fraser (1990) A rum lot. In: M.T. Salo (Ed.), 100 years of Gypsy Studies (Cheverly: The Gypsy Lore Society).

40. J. Ficowski (1951) Supplementary notes on the Mageripen code amongst Polish Gypsies. Journal of the Gypsy Lore Society, 30, pp. 123-132.

41. T.A. Acton (1971) The functions of the avoidance of Moxadi Kovels. Journal of the Gypsy Lore Society, 50, pp. 108-136.

\section{About the Authors}

Pavel Ciaian is a senior scientist and team leader of Economic Analyses of Food Supply Chains at the Joint Research Centre of the European Commission. Before joining the European Commission, Pavel held teaching and research positions at the Catholic University of Leuven and the Slovak Agricultural University in Nitra. He received a $\mathrm{PhD}$ degree in Economics from the Catholic University of Leuven. His research interests include policy impact analysis, institutional economics, food security, food chains and agricultural economics.

d'Artis Kancs is a senior scientist at the European Commission, Directorate-General Joint Research Centre, and is also affiliated with the Catholic University of Leuven. He has been leading several modelling teams at the European Commission, including a macro-economic modelling team in Sevilla, Spain and the Competence Centre on Modelling in Ispra, Italy. Before joining the European Commission, d'Artis has held various teaching and research positions in universities and research institutes in the UK, Germany, Austria, USA and Belgium. He received his $\mathrm{PhD}$ from the London School of Economics. 